\title{
Artificial Intelligence Use in Russian Governmental Bodies
}

By

\section{Dr.Olga A. Astafurova}

Candidate of Technical Sciences, Associate Professor, Head of the

Department of Information Systems and Mathematical Modeling - Volgograd Institute of Management, Branch of Russian Presidential Academy of

National Economy and Public Administration

Volgograd, Russian Federation

Correspondence: astoa@vlgr.ranepa.ru

Dr.Vadim V. Jakovenko

Candidate of Sciences (Economics), Associate Professor, Head of Department of Tax and Audit - Volgograd Institute of

Management, Branch of Russian

Presidential Academy of National

Economy and Public Administration

Volgograd, Russian Federation

Correspondence: yakovenkovv@vlgr.ranepa.ru
Dr.Alexsander P. Almosov

Candidate of Sciences (Economics), Associate Professor, Deputy Director -

Volgograd Institute of Management,

Branch of Russian Presidential Academy

of National Economy and Public Administration

Volgograd, Russian Federation Correspondence: almosovap@vlgr.ranepa.ru

\section{Dr.Elena V. Timacheva} Candidate of Sciences (Economics), Associate Professor of the Chair of Economy and Finances of Volgograd Institute of Management, Branch of Russian Presidential Academy of

National Economy and Public Administration

Volgograd, Russian Federation Correspondence: borisova_e@mail.ru 


\begin{abstract}
Intense interest to the artificial intelligence that can be seen nowadays is provoked first of all by expanding capacities of computing, its speedwork, operation economy of the hardware component, new opportunities of tele-communications as well as achievements in the sphere of working with the big data.

Using artificial intelligence in government affairs is connected with using different purpose information analysis systems as well as implementing Situation centres.
\end{abstract}

Situation centres are aimed at operational management in smart mode as well as strategic planning.

The Super services developed in Russia should also be mentioned in this respect. Super services are the complexes of state services grouped by typical real-life situations. They can be obtained fast-track on-line. Application of the artificial intelligence is possible not only within a country or a region but as well within the activity of one separate state body.

One of the time-consuming issues for employees of the state sector is processing citizen appeals. The procedure of processing citizen appeals is subject to regulation; it demands observance of 
dates. In this case it is reasonable to use intellectual ECM-system (enterprise content management system).

For processing personal appeals and telephone calls can be used programs converting voice into text. For written appeals systems of optical recognition of symbols can be used.

Intelligence systems can be useful as well in processing input documents. They can be assigned to register, classify and transmit information into the system of electronic document workflow. They can also be delegated some functions of departmental managers. For instance, they can make a short review of the input document or on the basis of prior resolutions make up the project of resolution. Taking minutes at meetings can also be automatized. Personal receptions of citizens can be recorded and converted into text.

Key words: artificial intelligence (AI), digitalization, digital economy, situation center, super service, dashboard

\section{Introduction}

Modern technologies of artificial intelligence are based on the methods and algorithms developed several decades ago. Such directions of artificial intelligence as computer vision, natural language processing, computer-assisted instruction, image recognition trace their origin to the last century. 
At present expanding scope of application of the artificial intelligence in different spheres and modes of human activity is caused by the evolution of the faced challenges. Thus, such challenges as solving technical problems, image recognition, natural language understanding, theorem proving, playing chess and etc. gradually evolved into creative challenges connected with increasing human intellectual activity applied as well in research and information (situation) centers having no solution algorithm.

According to the $50 \%$ of experts the most important changes in the employee's environment are those that provide transition to digital economy and consequently increasing cognitive requirements to the anticipated results [1].

Creating subjects of social development meeting requirements of the globalization century in innovation, technological, educational spheres in Russian Federation is recognized to be the first-priority goal of social projection of technological breakthrough [2, 3, 4]. Besides in October 2019 National strategy of artificial intelligence development up to 2030 was approved by the Edict of the President of the Russian Federation «On Development of artificial intelligence» [5]. 
Improving hardware devices enabled the extended use of machine training as the way of implementing tasks set to the computer. Many researches of the artificial intelligence up to the beginning of XXI century were inspired by the perspective of creating a computer that is able to fulfil the tasks implemented by humans. For such kind of computers such terms as «strong artificial intelligence» or «artificially genic intelligence (AGI)» are used.

At present the increasing number of researches support developments in the sphere of specialized or weak artificial intelligence fulfilling specific tasks. In our perspective it's the most realistic scenario of development in this sphere.

Weak artificial intelligence can work in real-time mode but it extracts information from limited set of data. As a result this system is able to handle only with one particular problem it was taught to solve. Within weak artificial intelligence computers can outrival humans particularly concerning computation-intense operations, algorithmic problems, and at last when combined operations are executed in conformity with strict rules which imply searching and processing enormous aggregation of data for discovering regularities, anomalies and optimizing particular indices. 
Developing «weak» or specialized artificial intelligence is aimed at solving particular problems, however, it can release humans from heavy processes of simplify them.

Today artificial intelligence manages to solve a wide range of problems. For example, in March 2020 coronavirus fakes in the Krasnodar region of the Russian Federation were disclosed with the help of artificial intelligence [6].

New technologies and services constantly appear, however implementing innovations is slowed down by inflexibility of the legislation. Accepting a new act often takes more time than developing a technical innovation. Many countries conduct research in the sphere of artificial intelligence. We should take into consideration their experience of creating «regulatory sandboxes» that enable to leave behind some regulations at the moment of creating and testing new advance developments and in case the testing succeeds enter the market without any risk to violate current legislation. «Regulatory sandboxes» are used in China, the USA, Australia, Great Britain, Bahrain, Canada and other countries. In Russia on the $17^{\text {th }}$ of March 2020 the State Duma pass in its first reading draft of a bill about creating such an testing site in Moscow. 
The consequences of implementing intelligence systems are still being discussed. Some experts consider that artificial intelligence threatens the society, other oppose them [7]. The necessity of considering application of intelligent systems within digital economy is comprehensively described in reference [8] including studying many factors and vectors of development.

\section{Situation centers}

The basis of artificial intelligence is big data. At the conference TAdviser SummIT, that took place on the $27^{\text {th }}$ of November 2019 Georgiy Lagoda Deputy Director General of State Company «Software productT» told that over the last two years over $95 \%$ of world data have been generated at that over $90 \%$ of them have not been structured yet.

In the fastchanging world management processes should be provided with data actual at the moment. Often for instance in case of emergency data should be taken from the site of event and analyzed in real-time operation. Such functions are executed by Situation centers.

At present in Russian Federation there are the following functioning situation centers: 
the President of Russian Federation, Administration of the President of Russian Federation, Government of Russian Federation, Security Council of Russian Federation, Plenipotentiary of the President of Russian Federation in federal districts, federal executive authorities, governmental authorities in constituent entities of the Russian Federation and other - in total over 80 objects. Situation centers develop unequally. Their development starts with visualization of obtained on-line data by means of dashboards; further development implies creating cognitive centers. Chairman of the Government of the Russian Federation approved the Plan of modernization works and creating new situation centers. By the end of 2020 a considerable number of such information objects are planned to have been put into operation within developing the system of distributed situation centers working on the basis of unified liaison protocol.

Situation centers face challenges of increasing effectiveness of state administration. big data analytics is more and more used in the work of government bodies. The infrastructure of the situation center enables to analyze and visualize major volumes of information, conduct analytical processing of operational data in groups. Situation centers are aimed at both operational management in smart mode and strategic planning as well. 
Cutting time is one of the main goals of the situation center. Using special means and presentation graphics enables to present the problem in system view and to solve it quickly. Using intelligent systems including cognitive subsystems enables to optimize the procedure of data processing that leads to more accurate analysis of economic situation and efficiency of taken decisions aimed at resolving such a situation. [9].

Training specialists for situation centers is one of predeterminants of its successful functioning. The importance of training such specialists is supported by many researchers. [10-12]. In Russia there are organizations In Russia there are some organizations whose activity significantly stimulates implementing technologies in situation center aimed at setting and reaching goals. The most famous ones are represented by: Innovation development club (http://www. reflexion.ru/club/), headed by V.Y.Lepskoy, the Center of development technologies for administrative and business structures (http:// www.razvitie-plan.ru/) headed by G.G. Malinetskiy, research-and-development center of creative thinking of Moscow Academy of Economics and Law headed by A.V. Shevyrev (www.ewrikasmc.ru). Volgograd Institute of management, Russian Presidential Academy of National Economy and Public Administration that the authors of this article have 
affiliation with train future managers using for this purpose training situation center. The center is used for acquiring skills of collecting information about the object and its external environment, estimating situation, analyzing collected information, predicting behavior of the controlled object, planning variants of management actions and fixing solution in the document.

\section{Super services}

The Super services developed in Russia should also be mentioned in this respect. Super services are the complexes of state services grouped by typical real-life situations. They can be obtained fast-track on-line.

The principle of rendering state services "by life situation" enables the citizen to write one application for the whole package of services connected with certain life events. Digital transformation of state and municipal services is carried out within the Federal project «Digital state administration» of the national program «Digital economy of the Russian Federation». First five prototypes were presented for estimation in July 2019. The following prototypes of super services by life situations were considered: «Child birth», «Entering the Higher educational institution on-line», «Moving to the other region», «Death of a 
relative» and «Digital execution». In November the Russian were invited to estimate 5 more super services: «Labour relations online», «Digital education documents on-line», «My health on-line», «On-line help for disabled», «Property on-line». Recently one more prototype «Social support on-line» has appeared. This super service informs citizens about privileges and helps them to understand how to use them. The pages of new super services appeared in the appropriate section of State services Web portal. Besides super services mono services that can be presented as a particular case of super services are developed as well. At present there is the number of mono services being optimized among them are the following: migration registration, tax declarations, cadastral registration and provision of information of Unified State Register of Taxpayers, issuing sanitary and epidemiological inspection reports, issuing communication service licenses and etc. Some state services are supposed to be made proactive, i.e. they will be provided automatically without submitting an application. Unfortunately at present it is impossible to do it since only written documents have legal force. However, as soon as digital data stored in different government bodies are legally recognized some services can be rendered automatically. For instance, when a citizen 
of the Russian Federation reaches a definite age the process of issuing passport starts automatically.

Providing effective interaction of a citizen with government bodies is the major priority in developing intelligent systems of new generation for the government bodies.

\section{Artificial intelligence in the activity of a single government body}

The right of the citizens to appeal to the government bodies is attached by Constitution of Russian Federation. According to the data of the Federal service of public statistics citizens use this right rather actively. For instance, the total number of the registered citizens appeals in Public health service Committee of the Volgograd region over 9 months of 2019 made up 7933. Consequently, processing citizens appeals became one of the most time-consuming issues for public officers. The order of processing citizens appeals is subject to regulation; it demands observance of dates. In this case it is reasonable to use ECM-systems. For example, the system itself can find out from the text of appeal what category it can be referred to (claim, application, offer), classify the type of issue using nomenclature as well as assign specialist and send him the appeal. Thus, the specialist working with the citizen 
application can devote more time to the problem or to answering the question.

In case of personal appeal to a government body or by phone programs converting voice into text. can be used. For written appeals systems of optical recognition of symbols can be used.

Processing input documents is not less time-consuming as well. Intelligence systems can be useful in this respect as well; they can be assigned to register, classify and transmit information into the system of electronic document workflow. It will enable to minimize the risk of human mistakes, to raise the speed of processing documents, release some time which an office worker can spend on implementing tasks and deeper processing of output documents.

They can also be delegated some functions of departmental managers. For instance, they can make a short review of the input document or on the basis of prior resolutions make up the project of resolution, define executor of the task, develop a typical text of the task and etc. Taking minutes at meetings can also be automatized. If personal receptions of citizens are recorded and converted into text they will contain every detail. 
Citizens appeals to government bodies for obtaining services can be easier due to one more instrument, i.e. prefilling application forms on the basis of downloaded scans of documents. Today the documents are downloaded at the last stages of submitting an application. It takes citizens from 15 to 30 minutes to fill the form of an application. If the document are processed by artificial intelligence, it will release citizens from filling in additional fields. All necessary information will have already been filled and the only thing the applicant will have to do is to check the correctness of automatic data filling in the application submitted for obtaining a state service. Thus submitting any application will take in average up to 5-10 minutes necessary for downloading the package of documents.

\section{Conclusions}

One of the main missions of the artificial intelligence is to release people from heavy, monotonous works negatively influencing human health. Artificial intelligence technologies will help to make the world more transparent and predictable. However, there can be some risks connected with using artificial intelligence. For instance, algorithms that were built and developed on the basis of uncleansed data can work improperly. Such automatization can 
inflict substantial damage. Moreover, algorithms can express their developer's opinion and that is why be subjective.

There are also some other risks. Data leakage can bring major risks for every citizen as well.

The specifics of data handling require peculiar consideration including specifics of personal data handling; it's necessary to give priority to the issues of legislative regulation. Hopefully the future world will be able to provide data confidentiality and prevent data abuse.

Projects of implementing artificial intelligence in government bodies positively effect information infrastructure and their implementation has social effect as well.

\section{References}

1. Kupriyanovskiy V.P., Sinyagov S.A., Lipatov S.I. International Journal of Open Information Technologies ISSN: 2307-8162 vol. 4, no. 2, 2016.

2. Lepskiy V.Y., Analytics of assembling subjects of development, M.:Cogito-Center, 2016

3. Stuart A. Umpleby, Tatiana A. Medvedeva \& Vladimir Lepskiy. Recent Developments in Cybernetics, from 
Cognition to Social Systems. // Cybernetics and Systems, 2019. Volume 50, Issue 4, pp. 367382. https://doi.org/10.1080/01969722.2019.1574326

4. Lepskiy, V.E., Avdeeva, Z.K., Raikov, A.N. Disruptive Situation Management in Digital Economy. Proceedings of 2018 11th International Conference "Management of LargeScale System Development", MLSD 2018 DOI: 10.1109/MLSD.2018.8551949

5. The decree of the President of the Russian Federation from May 9, 2017 № 203 «Strategy of information society development in the Russian Federation for 2017-2030

6. https://kubnews.ru/obshchestvo/2020/03/17/iskusstvennyyintellekt-pomog-razoblachit-rasprostraniteley-feykov-okoronaviruse-v-krasnodarskom-kr/

7. Kath Lockett dated from 11 November 2019 Using power of technologies https://www.iso.org/ru/news/ref2451.html

8. Holford, 2018 Holford W.D. The future of human creative knowledge work within the digital economy / Futures

9. Fedotova M.A. Intellectual systems in research and information (situation) centers within digital transformation // Moscow Economic Journal, 2019. №1, P. 1-12 
10. The student training system based on the approaches of gamification Shakhovska N., Vovk O., Holoshchuk R., Hasko R.Advances in Intelligent Systems and Computing. 2020. Vol. 938. P. 579-589.

11. Information technologies for teaching children with asd Andrunyk V., Shestakevych T., Pasichnyk V., Kunanets N. Advances in Intelligent Systems and Computing. 2020. Vol. 938. P. 523-533.

12. Electrical engineering disciplines teaching system for students with special needs Bobalo Y., Stakhiv P., Shakhovska N., Hamola O. Advances in Intelligent Systems and Computing. 2020. Vol. 938. P. 590-599. 